\title{
Tolerance of Shore Crabs to Tetrodotoxin and Saxitoxin and Antagonistic Effect of Their Body Fluid against the Toxins
}

\author{
Kunio Yamamori, ${ }^{* 1}$ Susumu Yamaguchi, ${ }^{* 2}$ Eisei Maehara, ${ }^{* 1}$ \\ and Takashi Matsui*3 \\ (Received December 13,1991)
}

\begin{abstract}
Lethal effects of tetrodotoxin (TTX) and saxitoxin (STX) on 6 species of nontoxic marine crabs, as well as effects of the toxins on their nerves, were investigated. There was wide variance among species examined for the lethal effect of TTX and STX. The tolerances of nerves are almost compatible to lethal tolerance with the exception of Hemigrapsus sanguineus. This species showed relatively high resistance to TTX, but its nerve was at almost the same level of tolerance as those of other TTX-sensitive crabs. In order to elucidate the mechanism for high TTX-resistance in $H$. sanguineus, nerve tolerance was measured in the presence of its body fluid. The body fluid reduced the effect of TTX on the nerves, while no effect was observed for STX. It is also confirmed that pre-injection of the body fluid of $H$. sanguineus into a mouse was effective to some extent in protecting the mouse from TTX attack.
\end{abstract}

The puffer fish toxin tetrodotoxin (TTX) and paralytic shellfish toxins are potent neurotoxins and have been found to be distributed widely from microorganisms to amphibians. ${ }^{1-5)}$ The toxins exert their toxic actions by specifically blocking the voltage-sensitive sodium channels in nerve and muscle membranes. ${ }^{e, 7)}$ It was found that xanthid crabs, Zosimus aeneus and Atergatis floridus contained not only paralytic shellfish toxins but also TTX. ${ }^{8)}$ These crabs had extremely higher tolerance to the toxins than nontoxic crabs. ${ }^{\theta-10)}$ Low response of the nerves to the toxins observed in these crabs may explain high resistance to the toxins. ${ }^{11}$ From the above fact, it could be easily supposed that an animal with high tolerance to toxins may contain toxins or have the capability to accumulate them. ${ }^{12,13)}$ Therefore, we conducted a survey of the resistance to TTX and saxitoxin (STX, one of the paralytic shellfish toxins) not only of the marine crabs which have been regarded as nontoxic crabs, but also of their nerves. It was confirmed in the present work, that there was wide variance among species examined in lethal effect of TTX and STX and that the toleraces of nerves are almost compatible to lethal tolerance with the exception of Hemigrapsus sanguineus. The discrepancy in the tolerance to TTX of $H$. sanguineus could be easily explained if we consider the existence of an anti-TTX substance in the crab body fluid. In order to confirm this assumption, we conducted measurements of nerve tolerance in the presence of the body fluid of $H$. sanguineus and obtained evidence that the body fluid of $H$. sanguineus could reduce the toxicity of TTX for $\mathrm{crab}$ and their nerves, but the body fluid of other crabs could not. It is also confirmed that preinjection of the body fluid of $H$. sanguineus into a mouse was effective to some extent in protecting the mouse from TTX challenge. The present paper reports these results.

\section{Materials and Methods}

Crabs

The crabs used in this experiment were Atelecyclidae, Telemessus acutidens (Average body weight \pm standard deviation $26.2 \pm 6.8 \mathrm{~g}$, number of crabs used 82); Portunidae, Ovalipes punctatus $(22.5 \pm 12.2 \mathrm{~g}, \quad 70) ;$ Grapsidae, Pachygrapsus

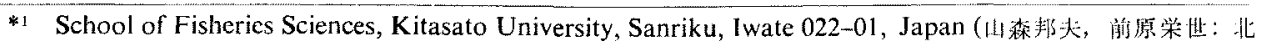
里大学水虐学部).

*2 Department of Food Science and Technology, Tokyo University of Fisheries, Minato, Tokyo 108, Japan

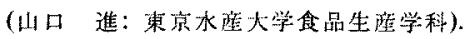

*3 Department of Fisheries, Faculty of Agriculture, The University of Tokyo, Bunkyo, Tokyo 113, Japan (松居 隆: 東京大学囦学部水碛学科). 
crassipes $(9.1 \pm 6.0 \mathrm{~g}, 30)$, Hemigrapsus sanguineus $(13.2 \pm 6.8 \mathrm{~g}, 78), \quad H$. penicillatus $(10.1 \pm 2.7 \mathrm{~g}$, $35)$, and Gaetice depressus $(3.1 \pm 1.8 \mathrm{~g}, 57)$. Live specimens of 6 species of marine crabs were caught from June, 1989 to January, 1990 at Okirai Bay, Yoshihama Bay, and Ohfunato Bay in Iwate Prefecure, Japan, transported to the laboratory, and reared in a tank until use.

\section{Tetrodotoxin and Saxitoxin}

Crystalline TTX (Sankyo Co., Ltd., Tokyo) was dissolved in $0.02 \mathrm{M}$ acetic acid and diluted with the same solution to obtain a series of concentrations. TTX was assayed by the official method using ddY strain male mice and expressed in mouse units (MU) or nanomoles. ${ }^{14}$ ) One MU was defined as the amount of TTX killing a $20 \mathrm{~g}$ mouse in $30 \mathrm{~min}$. In converting from MU to nanomoles, 319 and $0.22 \mu \mathrm{g} / \mathrm{MU}$ were used as the molecular weight and coversion factor for TTX, respectively. ${ }^{14)}$

STX was purchased from Calbiochem. Co., Ltd. and the toxin solution (One $\mu \mathrm{mol}$ per $\mathrm{ml}$ in $100 \mathrm{~mm}$ acetic acid) was diluted with $0.02 \mathrm{M}$ acetic acid to obtain a series of concentrations. STX was assayed by the official method using ddY strain male mice and expressed in mouse units $(M U){ }^{15)}$ One $M U$ was defined as the amount of STX killing a $20 \mathrm{~g}$ mouse in $15 \mathrm{~min}$.

\section{Lethality Test}

The volume of TTX or STX solution was fixed at $1 \%$ of the body weight of the crab. The calculated volume was injected into the basal part of the right fourth walking leg of each crab. Immediately after injection, the crabs were returned to the tank and observed for $2 \mathrm{~h}$. The crabs were judged to be dead when they did not respire nor respond to physical stimuli with forceps.

\section{Crab Leg Nerve Preparation and Electrophysio- logical Experiment ${ }^{*}$}

The crab leg (pereiopod) was excised at the basiisquium segment or was obtained in some instances by induced autotomy. The sensory nerve was isolated from the pereiopod by cutting the arthrodial membrane and joints of the leg segments and carefully pulling out and removing the leg segments, leaving the nerve attached to

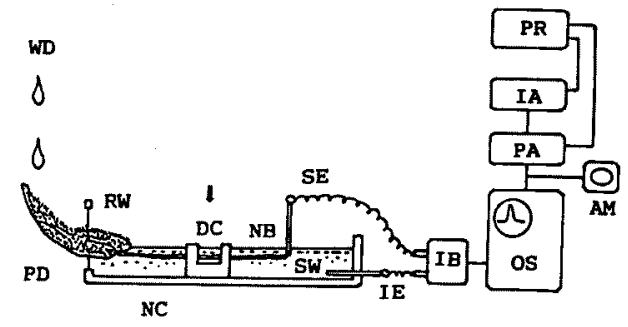

Fig. 1. Electrophysiological set-up diagram employed for the crab leg sensory nerve bioassay. WD, water drop; PD, pereiopod dactyl; RW, rubber wall; NC, nerve chamber; DC, drug chamber; NB, nerve bundle; SE, suction electrode; SW, sea water; IE, indifferent electrode; IB, input box; OS, oscilloscope; AM, audio monitor; PA, pre-amplifier; IA, integrator amplifier; $P R$, pen recorder. The arrow shows the place for drug insertion.
A)

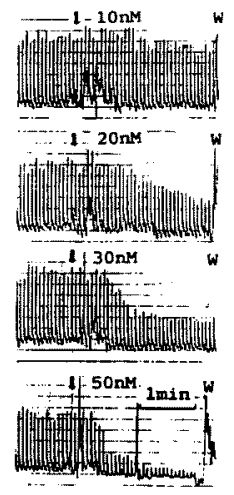

B)

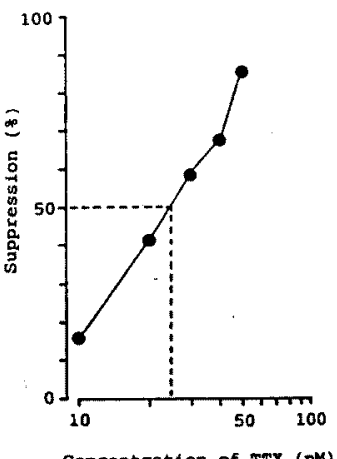

Concentration of TTX (nM)
Fig. 2. A) Representative sample recordings of the crab leg sensory nerve preparation. The arrow shows the addition of various concentrations of TTX. W: Washing. B) Dose response curve of the suppression of the action potentials of the nerve of Hemigrapsus penicillatus induced by various concentrations of TTX.

the distal dactyl segment which possess the mechanical and chemical receptor sensilla (Fig. 1). The dactyl segment was inserted through a rubber wall and placed just under the filtered sea water bottle. The sensory sensilla were stimulated by dropping sea water from a height of $10 \mathrm{~cm}$ on the dactyl tip at a fixed interval. The action

* J. C. Freitas, K. Yamamori, S. Sato, T. Ogata, and M. Kodama: Sensory nerve of crustacean leg as a pharmacological tool for the neurotoxin screening, in "Abstract of the IV Annual Meeting of Federation of Brazilian Societies for Experimental Biology", Caxambu, Minus Gerais, Brazil, 1989, p. 224 (in Portuguese). 
potentials generated by the sea water drop stimulation were recorded at the other end of the nerve chamber by a polyethylene suction electrode. The action potential discharges recorded from the nerve bundle end were amplified, integrated (time constant $0.3 \mathrm{~s}$ ), and recorded on a polygraph (Nihon Kohden, RM-25). The integrated action potential discharges were recorded before, during, and after TTX or STX addition into the drug chamber (Fig. 2), and the response measured as the height of the integrated action potential discharges induced by each sea water drop stimulus.

The tolerance of a nerve preparation was evaluated as follows: The integrated amplitudes of action potentials were measured at 2 min after the addition of the toxin at various toxin concentrations and then a calibration curve was made by plotting calculalted suppression rate $(\%)$ versus toxin concentration (nM). Median effective concentration was estimated by interpolation using a straight line connecting the two points nearest to $50 \%$ suppression, one above and one below. The control experiment was performed by filling the drug chamber with sea water $(100 \mu l)$. For testing the antagonistic effect of body fluids against toxins, the same procedure was performed by replacing sea water with the body fiuid.

\section{Collection of Crab Body Fluid}

The body fluid was withdrawn from the body cavity of live specimens with a syringe previously wet with $0.1 \mathrm{~m}$ sodium oxalate to prevent coagulation. The body fluid was centrifuged at 3.000 rpm for $15 \mathrm{~min}$ and the supernatant was passed through a membrane filter (Millipore Type HA, $0.45 \mu \mathrm{m})$.

\section{Effect on a Mouse}

The Body fluid of $H$. sanguineus was divided into two fractions by filtration through an Amicon, Centricon-10 membrane. The fraction retained on the filter was resuspended in an original volume of sea water (designated as the over 10,000 molecular weight fraction, $>10,000 \mathrm{Da}$ ) and the filtrate was designated as the less than 10,000 molecular weight fraction $(<10,000 \mathrm{Da})$. The mice were pre-injected with $0.2 \mathrm{~m} l$ of the fractionated body fluid intraperitoneally (IP) or intravenously (IV), and then after $5 \mathrm{~min}$, the mice were challenged with TTX at several doses by the standard method. ${ }^{(4)}$

\section{Results and Discussion}

Tolerance of Shore Crabs to TTX and STX

The lethality towards shore crabs due to TTX

Table 1. Tolerance of shore crabs to tetrodotoxin and saxitoxin

\begin{tabular}{|c|c|c|c|c|}
\hline \multirow[b]{2}{*}{ Species } & \multicolumn{2}{|c|}{ Tetrodotoxin } & \multicolumn{2}{|c|}{ Saxitoxin } \\
\hline & Dose* & $\begin{array}{l}\text { No. of dead/ } \\
\text { No. of examined }\end{array}$ & Dose $^{* *}$ & $\begin{array}{c}\text { No. of dead/ } \\
\text { No. of examined }\end{array}$ \\
\hline \multirow{3}{*}{ Telmessus acutidens } & 0.2 & $0 / 10$ & 6.0 & $1 / 10$ \\
\hline & 0.3 & $9 / 15$ & 7.0 & $5 / 10$ \\
\hline & 0.4 & $9 / 10$ & 8.0 & $6 / 6$ \\
\hline \multirow[t]{3}{*}{ Ovalipes punctatus } & 0.03 & $1 / 5$ & 2.0 & $5 / 14$ \\
\hline & 0.05 & $5 / 5$ & 3.0 & $10 / 18$ \\
\hline & & & 4.0 & $6 / 6$ \\
\hline \multirow[t]{3}{*}{ Pachygrapsus crassipes } & 0.02 & $1 / 5$ & 1.0 & $0 / 5$ \\
\hline & 0.04 & $4 / 5$ & 2.0 & $2 / 5$ \\
\hline & & & 4.0 & $4 / 5$ \\
\hline \multirow[t]{3}{*}{ Hemigrapsus sanguineus } & 10 & $0 / 3$ & 0.05 & $3 / 10$ \\
\hline & 20 & $4 / 10$ & 0.1 & $4 / 5$ \\
\hline & 30 & $7 / 10$ & & \\
\hline \multirow{2}{*}{ Hemigrapsus penicillatus } & 0.02 & $1 / 5$ & 0.2 & $1 / 7$ \\
\hline & 0.03 & $7 / 8$ & 0.4 & $4 / 5$ \\
\hline \multirow{6}{*}{ Gaetice depressus } & 0.02 & $0 / 5$ & 0.03 & $0 / 3$ \\
\hline & 0.04 & $5 / 5$ & 0.05 & $2 / 4$ \\
\hline & & & 10 & $0 / 5$ \\
\hline & & & 13 & $1 / 7$ \\
\hline & & & 16 & $4 / 13$ \\
\hline & & & 32 & $5 / 5$ \\
\hline
\end{tabular}

* MU/20 g of body weight. 
Table 2. Tolerance of nerves of shore crabs to tetrodotoxin and saxitoxin (nM)*1

\begin{tabular}{|c|c|c|}
\hline Species & Tetrodotoxin*2 & Saxitoxin*2 \\
\hline Telmessus acutidens & $147 \pm 110(3)$ & $1,040 \pm 651(2)$ \\
\hline Ovalipes punctatus & $28 \pm 11(2)$ & $357 \pm 148$ \\
\hline Pachygrapsus crassipes & $56 \pm 18(3)$ & $249 \pm 159(3)$ \\
\hline Hemigrapsus sanguineus & $54 \pm 27(9)$ & $96 \pm 56(4)$ \\
\hline Hemigrapsus penicillatus & $31 \pm 13(4)$ & $54 \pm 27(4)$ \\
\hline Gaetice depressus & $37 \quad$ (1) & $180 \pm 14(2)$ \\
\hline
\end{tabular}

* Toxin concentration required to suppress $50 \%$ of action potential discharges.

*2 Mean $\$$ standard deviation (number of examined).

Table 3. Antagonism of body fluids of shore crabs against tetrodotoxin and saxitoxin

\begin{tabular}{|c|c|c|c|}
\hline \multirow{2}{*}{ Toxin } & \multicolumn{2}{|c|}{ Species } & \multirow{2}{*}{$\begin{array}{l}\text { Toxin concentration required } \\
\text { to suppress } 50 \% \text { of action } \\
\text { potential discharges (nM) }\end{array}$} \\
\hline & Body fluid & Nerve & \\
\hline \multirow[t]{5}{*}{ TTX } & H. sanguineus & H. sanguineus & $1,875 \pm 991(4)$ \\
\hline & H. sanguineus & H. penicillatus & $2,833 \pm 1,387(3)$ \\
\hline & H. sanguineus & O. punctatus & 1,000 \\
\hline & H. penicillatus & H. penicillatus & $0(2)$ \\
\hline & O. punctatus & H. sanguineus & (1) \\
\hline \multirow[t]{2}{*}{ STX } & H. sanguineus & H. sanguineus & $75 \pm \quad 35(2)$ \\
\hline & $G$. depressus & H. sanguineus & 300 \\
\hline
\end{tabular}

* Mean \pm standard deviation (number of examined).

administration to the body cavity is shown in Table 1. O. punctatus, $P$. crassipes, H. penicillatus, and $G$. depressus exhibited almost the same tolerance, ranging from $0.02-0.05 \mathrm{MU} / 20 \mathrm{~g}$ of body weight. $T$. acutidens had resistance ten times higher than that of the above three crabs and the lethal dose was $0.2-0.3 \mathrm{MU} / 20 \mathrm{~g}$. In comparison, $H$. sanguineus showed a very high resistance that was about 1,000 times stronger than that of sensitive crabs and its lethal dose was $20-30 \mathrm{MU} / 20 \mathrm{~g}$.

The tolerance of the crabs to STX is aslo shown in Table 1. Although $H$. sanguineus showed a high resistance to TTX, the resistance of this crab to STX was the lowest among 6 species, being $0.1 \mathrm{MU} / 20 \mathrm{~g}$. $H$. penicillatus was also susceptible to STX and was killed at 0.2-0.4 $\mathrm{MU} / 20 \mathrm{~g}$. $T$. acutidens, $P$. crassipes, and $O$. punctatus were more tolerant to STX, with lethal doses of $6.0-8.0,2.0-4.0$, and $2.0-4.0 \mathrm{MU} / 20 \mathrm{~g}$, respectively.

All 6 species used in this study were nontoxic as far as we tested, but the resistance against TTX and STX differed from species to species. Focusing on the lethal effect of TTX, the shore crabs were divided into three groups which exhibited high, medium, and low sensitivity to TTX. It was found that $H$. sanguineus had relatively high resistance to TTX, but even this level was much lower than those of toxic crabs, with $2,000 \mathrm{MU} / 20 \mathrm{~g}$ reported for Zosimus aeneus. ${ }^{10)}$

\section{Effects of TTX and STX on Shore Crab Nerves}

In Fig. 2, the effect of TTX on the nerve of $H$. penicillatus is shown as representative sample recordings. In this case, the action potential of the crab nerve was suppressed by $50 \%$ in $25 \mathrm{nM}$ TTX. All the results are summarized in Table 2. The values of resistance to TTX for 5 species, including $H$. sanguineus, were almost at the same level, ranging from 28 to $56 \mathrm{~nm}$, and the value for $T$. acutidens was $147 \mathrm{~nm}$, indicating that the nerve of this crab is more tolerant than those of other species. In the case of resistance to STX, that of the nerve of $T$. acutidens was the highest at $1,040 \mathrm{~nm}$, followed by $O$. punctatus, $P$. crassipes, and $G$. depressus at 357,249 , and $180 \mathrm{~nm}$, respectively. The resistances of $H$. sanguineus and $H$. penicillatus, however, were one tenth that of $T$. acutidens. With the exception of $H$. sanguineus to TTX, there was a tendency for highly tolerant crabs to show high $50 \%$ suppression concentrations.

Effect of Body Fluid on the Tolerance of Nerves against TTX and STX

As shown in Table 3, the body fluid of $H$. 
Table 4. Protection of mice from TTX poisoning by the fractionated body fluid of Hemigrapsus sanguineus

\begin{tabular}{ccccc}
\hline \multirow{2}{*}{$\begin{array}{c}\text { TTX administerd } \\
\text { (MU/20 } \mathrm{g} \text { of mouse) }\end{array}$} & \multicolumn{2}{c}{ TTX found (MU/20 g of mouse) } \\
\cline { 2 - 4 } & $<10,000 \mathrm{Da}$ & $>10,000 \mathrm{Da}$ & $<10,000 \mathrm{Da}$ & IV pre-injection \\
\hline 2.00 & 1.36 & $<1$ & & $>10,000 \mathrm{Da}$ \\
3.20 & 2.19 & $<1$ & 2.58 & 1.13 \\
5.33 & 4.22 & 1.11 & 5.62 & 1.39 \\
\hline
\end{tabular}

* The values are the averages of 5 mice.

sanguineus increased TTX-tolerance of the nerve of this crab to almost 40 -fold, judging from the TTX concentration at which the action potential was suppressed by $50 \%$. The body fluid was also effective in the antagonism of TTX action on the nerves of other specimens, such as $H$. penicillatus and $O$. punctatus. On the other hand, the body fluids of $H$. penicillatus and $O$. punctatus did not show any antagonistic effect involving the nerves of $H$. penicillatus or $H$. sanguineus. It should be noted that the body fluids of $\boldsymbol{H}$. sanguineus or $\boldsymbol{G}$. depressus did not have any antagonistic effect against STX action on the nerves of $H$. sangiuneus. This result clearly explains the high tolerance of $H$. sanguineus to TTX in spite of the high sensitivity of its nerves to the toxin. With relation to this result, Y. Li et al. recently reported that plasma from the bullfrog Rana catesbeiana contains a STX specific binding protein named saxiphilin which may play a role in the defense mechanism against STX poisoning. ${ }^{17}$ ) Ours is the first report to indicate the existence of substances in shore crab $H$. sanguineus body fluid which antagonize TTX action.

\section{Effect of Body Fluid to Mice Challenged with TTX}

Preliminary experiments using nerve preparations demonstrated that the effect of TTX on action potentials of crab nerves was clearly suppressed by the $>10,000 \mathrm{Da}$ body fluid fraction as well as by the non-fractionated body fluid of $H$, sanguineus (data not shown). In order to examine whether mice could be rescued from TTX poisoning, mice were previously injected with fractionated body fluid and were then challenged with TTX at doses of 2.0, 3.2, and 5.3 MU/20 g. The results are summarized in Table 4 , in which the values of MU found were calculated from the time of death of per-treated mice. Administration of the $<10,000 \mathrm{Da}$ fraction did not show any antagonistic effect by either IP or
IV injection. The slight reduction observed in TTX might be due to a salt effect on the toxicity of TTX. ${ }^{2)}$ On the other hand, IP administration of the $>10,000 \mathrm{Da}$ fraction definitely reduced the toxicity of TTX from 2.0,3.3, and 5.3 MU to $<1.0,<1.0$, and $1.1 \mathrm{MU}$, respectively, and the IV administration of the $>10,000 \mathrm{Da}$ fraction also reduced the toxicity of TTX from 3.3 and $5.3 \mathrm{MU}$ to 1.1 and $1.4 \mathrm{MU}$, respectively. Thus, the protecting effect of the crab body fluid from TTX poisoning was clearly demonstrated. This is the first report to show that the body fluid of a crab, in this case, $H$. sanguineus contains substances with molecular weight of over $10,000 \mathrm{Da}$ which antagonize TTX action. Studies are in progress to clarfy the mechanism involved in TTX antagonism.

\section{Acknowledgements}

This study was supported in part by Grant-inAid for Scientific Research from the Ministry of Education, Science, and Culture of Japan.

\section{References}

1) I. Tani: Toxicological studies on Japanese puffers. Teikoku Tosho, Tokyo, 1945, pp. 1-103. (in Japanese)

2) Y. Hashimoto: Marine toxins and other bioactive marine metabolites. Japan. Sci. Soc. Press, Tokyo, 1979, pp. 39-71.

3) F. A. Fuhrman: Tetrodotoxin, tarichatoxin, and chiriquitoxin: historical perspectives. Ann. NY Acad. Sci., 479, 114 (1986).

4) T. Yasumoto, H. Nagai, D. Yasumura, T, Michishita, A Endo, M. Yotsu, and Y. Kotaki: Interspecies distribution and possible origin of tetrodotoxin. Ann. NY Acad. Sci., 479, 44-51 (1986).

5) K. Hashimoto and T. Noguchi: Recent studies on paralytic shellfish poison in Japan. Pure and Appl. Chem., 61, 7-18 (1989).

6) T. Narahashi: Chemicals as tool in the study of excitable membrane. Physiol. Rev., 54, 813-889 (1974).

7) C.-Y. Kao and S.-L. Hu: Continuing roles of tetrodotoxin, saxitoxin, and their analogues in studies on ionic-channel functions, in "Mycotoxins and Phycotoxins ' 88 " (ed. by S. Natori, K. Hashimoto, and $\mathrm{Y}$. Ueno), Elsevier, Amsterdam, 1989 , pp. 417-423.

8) D. Yasumura, Y. Oshima, T. Yasumoto, A. C. Alcala, and L. C. Alcala: Tetrodotoxin and paralytic shellfish toxins in 
Philippine crabs, Agric, Biol. Chem., 50, 593-598 (1986).

7) K. Koyana, T. Noguchi, Y. Ueda, and K. Hashimoto Resistibility of toxic and nontoxic crabs against paralytic shellfish poison and tetrodotoxin. Nippon Suisan Gakkaishi, 49, $485-489$ (1983).

10) K. Daigo, O. Arahawa, T. Noguchi, A. Uzu, and K. Hashimoto: Resistibility of two xanthid crabs Zosimus aneus and Daira periata against paralytic shellfish poison and tetrodotoxin. Nippon Suisan Gakkaishi, 53, 881-884 (1987).

11) K. Daigo, T. Noguchi, A. Miwa, N. Kawai, and K. Hashimoto: Resistance of nerves from certain toxic crabs to paralytic shellfish poison and tetrodotoxin. Toxoicon, $\mathbf{2 6}$, 485-470 (1988)

12) C. V. Kao, and F. A. Fuhrman: Differentiation of the actions of tetrodotoxin and saxitoxin. Toxicon, 5, 25-34 (1967).

13) T. Saito, T. Noguchi, T. Harada, O. Murata, T. Abe, and K. Hashimoto: Resistibility of toxic and nontoxic pufferfish against tetrodotoxin. Nippon Suisan Gakkaishi, 51, 1371
(1985).

14) T. Kawdbata: Assay method for tetrodotoxin. in "Food Hygiene Exannination Manual", Vol. 2, (in Japanese), Environmenta! Healtb Bureau, Ministry of Health and Welfare, Tokyo, 1978, pp. 232-240.

15) T. Kawabata: Assay method for paralytic shellfish poison. in "Food Hygiene Examination Manual", Vol. 2, (in Japanese), Environmental Health Bureau, Ministry of Health and Welfare, Tokyo, 1978, pp. 240-244.

16) Y, Li and E. Moczydlowski: Purification and partial sequencing of saxiphilin, a saxitoxin-binding protein from the bullfrog, reveals homology to transferiin. J. Biol. Chem., $266,15481-15487$ (1991).

17) J. Mahara, G. L. Lukacs, Y. Li, S. Hall, and E. Mocxzydlowski: Pharmacological and biochemical properties of saxiphilin, a soluble saxitoxin-binding protein from the bulfrog (Rana catesbeiana). Toxicon, 29, 53-71 (1991). 